Journal of Engineering and Applied Sciences 14 (11): 3571-3574, 2019

ISSN: 1816-949X

(C) Medwell Journals, 2019

\title{
Vibration Analysis of Aircraft Wing under Gust Load
}

\author{
Majid Habeeb Faidh-Allah and Adawiya Ali Hamzah \\ Department of Mechanical Engineering, College of Engineering, University of Baghdad, Baghdad, Iraq
}

\begin{abstract}
This research will present numerical model of an aircraft wing to be tested under different types of loads. Three wings design were tested in this study to show the effect of wing design on the overall vibration behavior under gust load. The main layout of numerical work is divided into 2 main part: first one is the modeling of unmanned aircraft wing by using ANSYS environment (APDL) where a 3 dimensional models were totally simulated within the finite element solver with 3 different internal construction. While the second part is the performing of load effect on the whole structure of the wing where the simulation was carried out to guarantee that every point within the simulated structure is subjected to a very similar loading case of during it actual case. Modal analysis was performed also within the numerical part to investigate the most critical expected modes of vibrations. This research can be extended to have an experimental part by testing the wings under gust load within laboratory wind tunnel.
\end{abstract}

Key words: Aircraft wing, modal analysis, finite element method, ANSYS, dimensional models, tunnel, vibrations

\section{INTRODUCTION}

Balancing between mass and stiffness can be considered as a key by which the design can ensure both stability and controllability of a structure. A plethora of studies where noticed on how the designer can satisfy this balance between these 2 important factors. Waghulde et al. (2010) controlled of vibration for a smart beam was presented. This smart beam consists of actuators and sensors located at the root of a cantilever beam. Das et al. (2011) studied active vibration control. The vibration of a smart structure is suppressed by using counter directional force to the structure. The FEM of the smart plate is modeled by uses ANSYS-12 Software. Rahman and Alam (2012) perfumed vibration suppression of smart structure by using smart material (piezoelectric). The smart structure consists of a beam as the master structure and piezoelectric patches as the sensing and ctuation elements. Parameswaran et al. (2013) presented output feedback based on active vibration control has been accomplished on smart structure.

In this study the researchers worked on trying to balance between mass and stiffness of tested wing by considering various internal constructions as preliminary idea to ensure further enhancement if a smart controller be used. This study can be extended to be tested experimentally and to be controlled by one of available classic or modern controllers.

\section{MATERIALS AND METHODS}

Numerical model: In this study, 3 wings design of unmanned aircraft were tested within ANSYS environment with different internal construction. The main wing model scaled down by $(1 / 2.2)$. The aerofoil shape was NACA $(0006)$, i.e., symmetric airfoil with a maximum thickness of $(6 \%)$ of the chord length. Smi span length is $0.55 \mathrm{~m}$ while the chord length is about $0.1 \mathrm{~m}$. The general outline of both airfoil and wing shape are presented in Fig. 1 and 2, respectively. Shell 181 was selected to mesh the tested wing as it has high ability to discretise the curved structure with high degree of accuracy (Anonymous, 2014).

The first 3D Model was modeled as a solid body as stated in Fig. 3 using ANSYS APDL as by Chudy (2004). The 2nd model was a hollow model as stated in Fig. 4. The third model was stated in Fig. 5 the third model was tested with three longitudinal bars. Figure 6 shows the 4 th wing design was tested. It contains 7 stages (airfoils) and 3 longitudinal bars. The lines stated in Fig. 5 and 6 show the outline of wing's internal construction of the tested wings. Meshed Model of the tested wing is stated in Fig. 7 where the wings with its boundary conditions are presented.

$\mathrm{Z}$

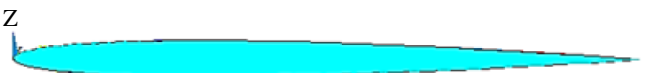

Fig. 1: Airfoil section of tested wing

Corresponding Author: Majid Habeeb Faidh-Allah, Department of Mechanical Engineering, College of Engineering, University of Baghdad, Baghdad, Iraq 


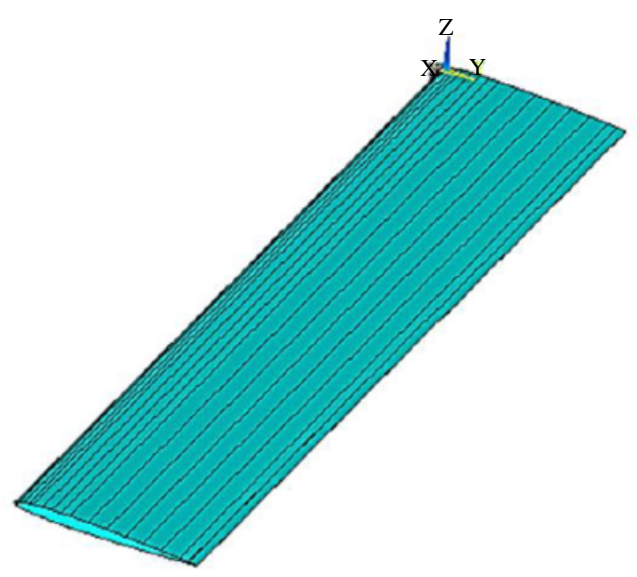

Fig. 2: Tested wing

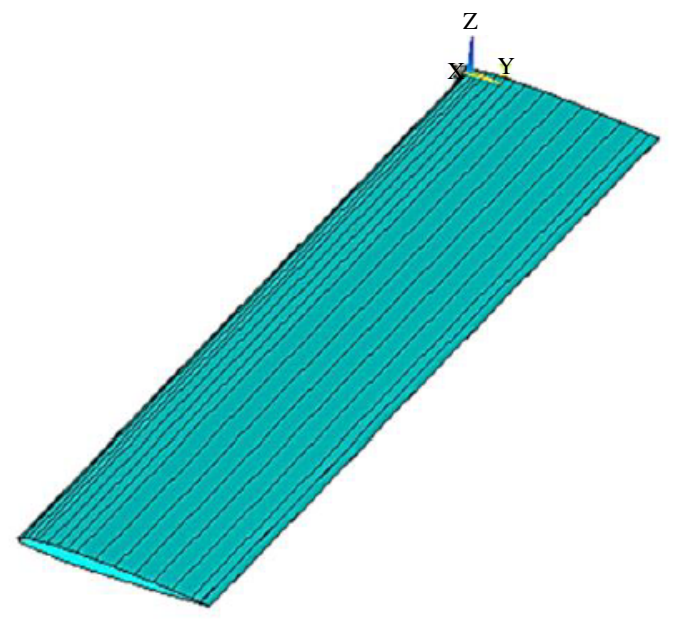

Fig. 3: 1st model

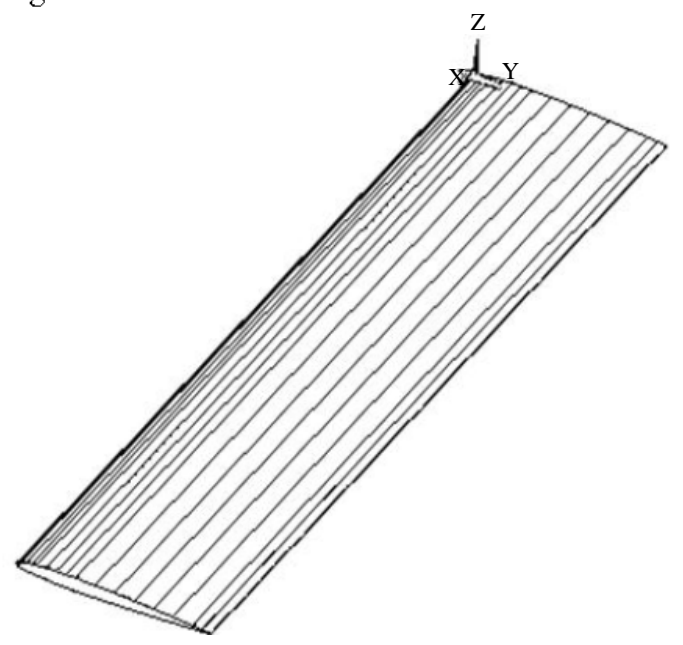

Fig. 4: 2nd model

Material properties of tested structure are stated. The model was subjected to gust load of $30 \mathrm{~N}$ applied as

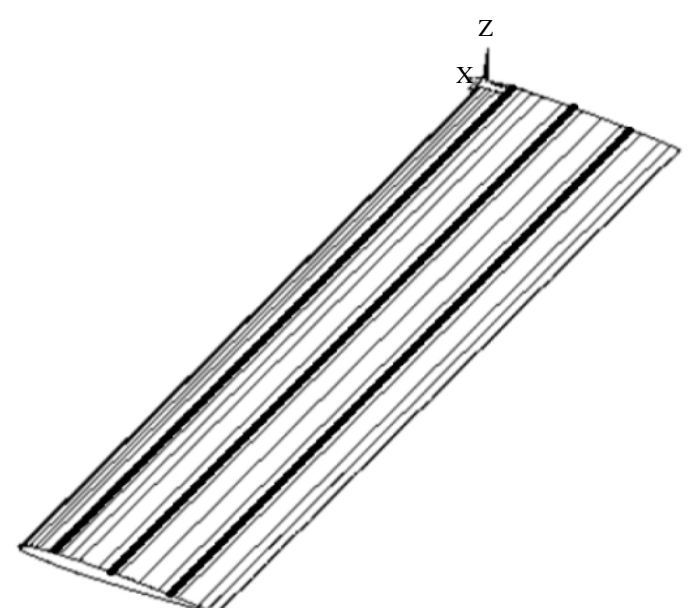

Fig. 5: 4th model

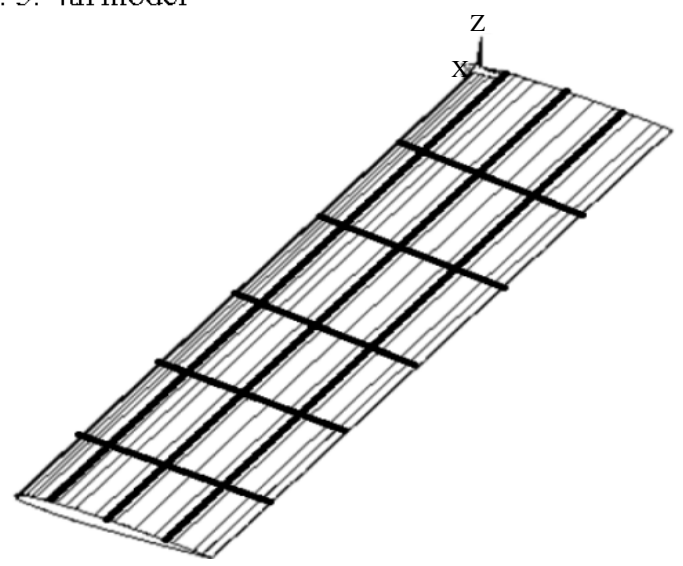

Fig. 6: 5th model

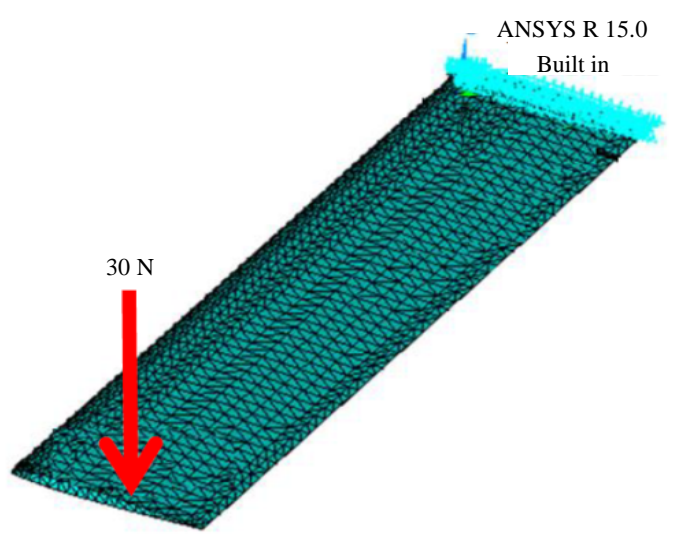

Fig. 7: Boundary condition

sudden load on the wing's tip. The main idea from this is to ensure the simulation of one of the most repeated phenomena happen to the aircraft wing (Chudy, 2004). Some of modeling steps like meshing were carried out based on ref. Hamzah (2017), modeling steps. 
Mechanical Properties epoxy-glass composite structure:

$$
\begin{array}{ll}
. & \mathrm{e}=1830 \mathrm{~kg} / \mathrm{m} \\
. & \mathrm{Ex}=40.51 \mathrm{GPa} \\
. & \mathrm{Ey}=13.96 \mathrm{GPa} \\
. & \mathrm{Ez}=13.96 \mathrm{GPa} \\
\text {. } & \mathrm{Gxy}=3.1 \mathrm{GPa} \\
\text {. } & \mathrm{Gyz}=1.55 \mathrm{GPa} \\
. & \mathrm{Gxz}=3.1 \mathrm{GPa} \\
. & \mathrm{vxy}=0.22 \\
. & \mathrm{vxz}=0.11 \\
. & \mathrm{vxz}=0.22
\end{array}
$$

\section{RESULTS AND DISCUSSION}

First modes of vibration for the 4 designs are stated in Fig. 8-11, respectively. In these figures it is clear that shape of the first mode of vibration is the same in each model as the general outline of the wing's external shape and design is the same. But the main difference in the mode of each tested design was the natural frequencies. It was noticed the hollow model of the tested wing shows the lowest natural frequency in comparison with all tested model. It is important to mention that the main cause of that was the mass distribution and stiffness of the tested model plays the most major role in this regard.

The solid model shows more increasing in natural frequency in comparison with the solid one. It is concluded that the balancing between both mass and stiffness can lead to more enhancement in the vibrational behavior of the structure. This conclusion was employed in the 3rd design that show further enhancement in the overall value of the wing's natural frequency. The best enhancement in the frequency was achieved in the 4th model in which the best balance was achieved. A comparison between natural frequencies values for each model is presented in Fig. 12.

Free responses of excited wings are presented in Fig. 13. In this research, these responses are presented as a preliminary input for extending this study in future to attenuate them by a feedback controller. In mentioned figure it is clear that settling time for all designs didn't exceed $4 \mathrm{sec}$. But in order to ensure economical fuel consumption one can decrease the wing's weight by balancing it with stiffness to reach the optimal vibration behavior under both free and controlled response.

As presented in mentioned figure, it was very clear that the solid wing's model had shortest settling time in comparison with hollow one that has the longest oscillation time. Although, the first design is the most settled one but high fuel consumption and controller

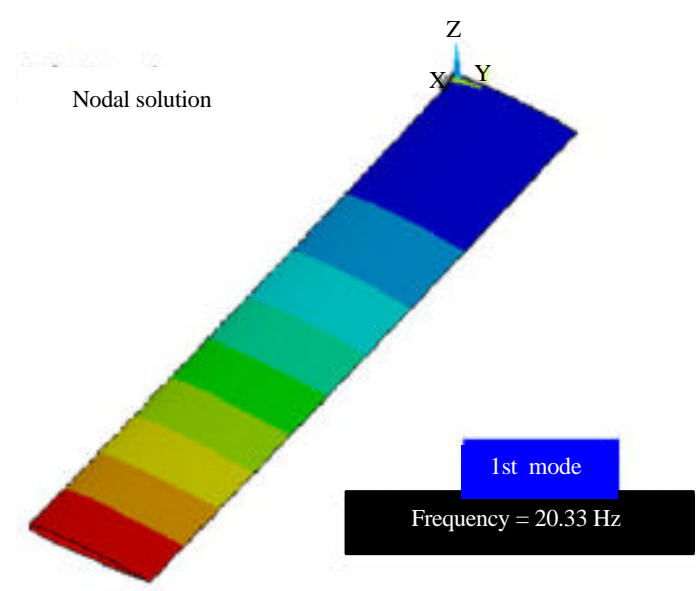

Fig. 8: 1st mode of 1st design

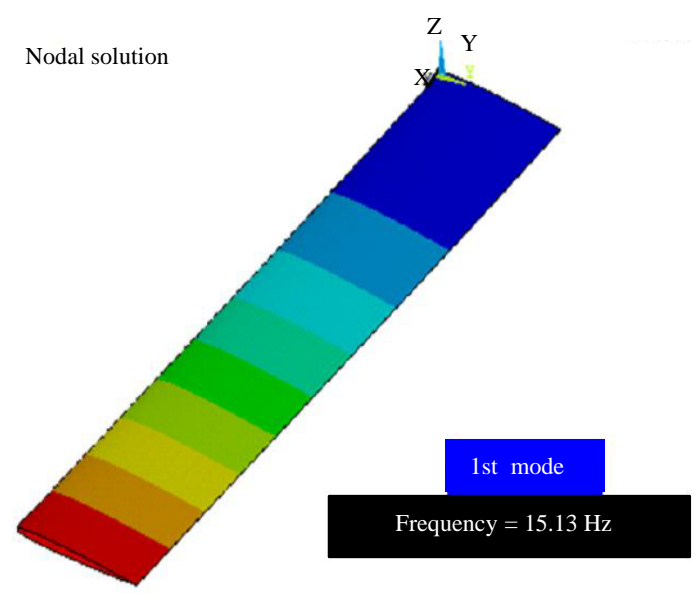

Fig. 9: 1st mode of 2nd design

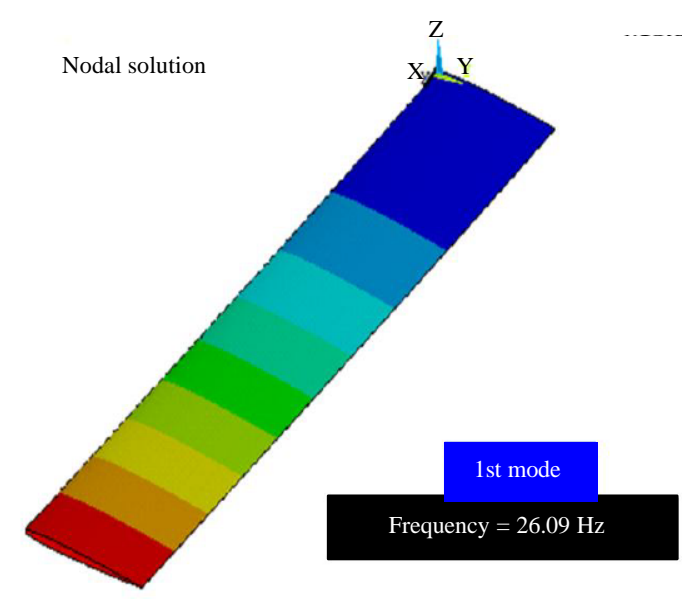

Fig. 10: 1st mode of 3rd design

required energy expected. Settling time of the 3rd wing design starts to be enhanced with a noticeable value in comparison with the both 1 st and 2 nd designs. 


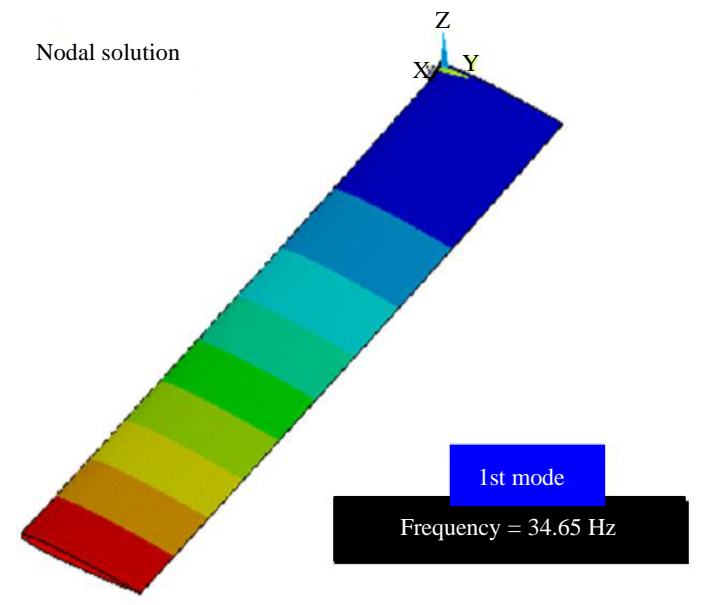

Fig. 11: 1st mode of 4th design

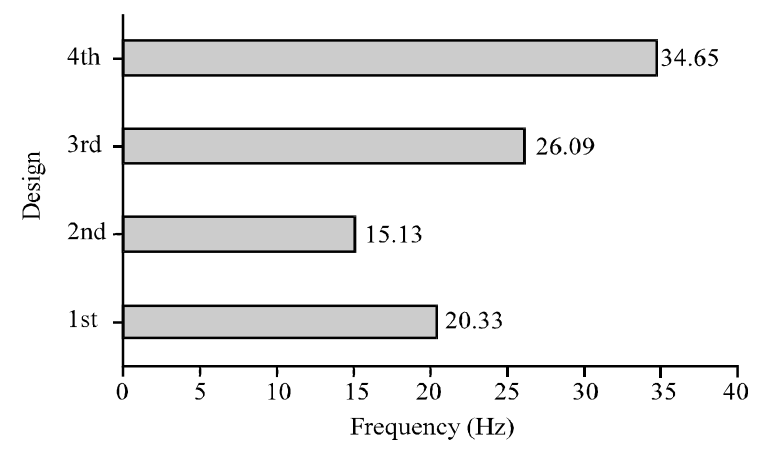

Fig. 12: Design's natural frequencies

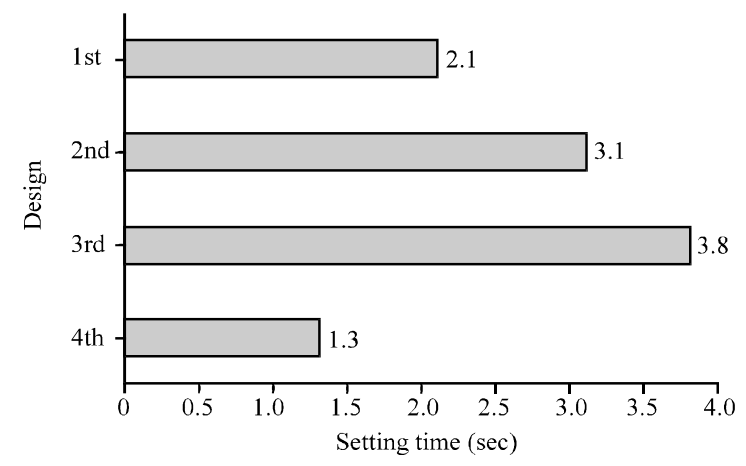

Fig. 13: Design's settling time

The best enhancement in the wing's oscillation time has been shown by the forth wing design as it shows the shortest oscillation time and highest natural frequency what makes it the optimum inner construction design that has and wide range of frequency and the most stable structure. Based on that, designer can ensure effective controller response and economical energy consumption.

\section{CONCLUSION}

Three wings with 3 different internal design contractions were presented under gust load. It was concluded that the highest degree of balancing between mass and stiffness can ensure the best frequency threshold and best period required to make the vibrated structure to be settle down. The main conclusion will lead to ensure that the low structural mass will definitely ensure smooth response and controller action if vibration controller be activated in future design.

\section{ACKNOWLEDGEMENT}

We feel obliged to present our great thanks and gratitude to those who have kindly and patiently supported in our research.

\section{REFERENCES}

Anonymous, 2014. ANSYS user manual (version 15.0). Ansys, Canonsburg, Pennsylvania, USA.

Chudy, P., 2004. Response of a light aircraft under gust loads. Acta Polytech., 44: 97-102.

Das, S., J. Baral and P. Chatterjee, 2011. Active vibration control of piezo-laminated cantilever beam. Ph.D Thesis, National Institute of Technology, Rourkela, Rourkela, India.

Hamzah, A.A., 2017. Vibrational behavior of three floors structure equipped with dampers. Intl. J. Mech. Mechatron. Eng., 17: 76-85.

Parameswaran, A.P., A.B. Pai, P.K. Tripathi and K.V. Gangadharan, 2013. Active vibration control of a smart cantilever beam on general purpose operating system. Defence Sci. J., 63: 413-417.

Rahman, N.U. and M.N. Alam, 2012. Active vibration control of a piezoelectric beam using PID controller. Latin Am. J. Solids Struct., 9: 657-673.

Waghulde, K.B., B. Sinha, M.M. Patil and S. Mishra, 2010. Vibration control of cantilever smart beam by using piezoelectric actuators and sensors. Intl. J. Eng. Technol., 2: 259-262. 